\title{
Decreased blood antioxidant capacity and increased lipid peroxidation in young cigarette smokers compared to nonsmokers: Impact of dietary intake Richard J Bloomer
}

Address: Department of Health and Sport Sciences, The University of Memphis, Memphis, TN, USA

Email: Richard J Bloomer - rbloomer@memphis.edu

Published: 8 November 2007

Nutrition Journal 2007, 6:39 doi:10.1186/1475-289/-6-39

This article is available from: http://www.nutritionj.com/content/6/I/39

(C) 2007 Bloomer; licensee BioMed Central Ltd.

This is an Open Access article distributed under the terms of the Creative Commons Attribution License (http://creativecommons.org/licenses/by/2.0), which permits unrestricted use, distribution, and reproduction in any medium, provided the original work is properly cited.
Received: 27 June 2007

Accepted: 8 November 2007

\begin{abstract}
Background: Blood of cigarette smokers routinely displays decreased antioxidant capacity and increased oxidized lipids compared to nonsmokers. This is thought to be due to both chronic exposure to cigarette smoke in addition to low intake of dietary antioxidants, and is a routine finding in veteran smokers. No study to date has determined the independent and combined impact of dietary intake and cigarette smoking on blood antioxidant capacity and oxidative stress in a sample of young, novice smokers.
\end{abstract}

Methods: We compared resting plasma antioxidant reducing capacity (ARC; expressed in uric acid equivalents), serum trolox-equivalent antioxidant capacity (TEAC), whole blood total glutathione, plasma malondialdehyde (MDA), and plasma oxidized low density lipoprotein (oxLDL) between 15 young ( $24 \pm 4$ years), novice smokers (pack-year history: $3 \pm 2$ ) and 13 nonsmokers of similar age ( $24 \pm 5$ years). Detailed dietary records were maintained during a seven-day period for analysis of total energy, macro- and micronutrient intake.

Results: ARC $\left(0.0676 \pm 0.0352\right.$ vs. $0.1257 \pm 0.0542 \mathrm{mmol} \cdot \mathrm{L}^{-1} ;$ mean $\left.\pm S D, p=0.019\right)$, TEAC $(0.72 \mathrm{I}$ \pm 0.120 vs. $\left.0.765 \pm 0.130 \mathrm{mmol} \cdot \mathrm{L}^{-1}, \mathrm{P}=0.24\right)$ and glutathione $\left(835 \pm 143\right.$ vs. $898 \pm 168 \mu \mathrm{mol} \cdot \mathrm{L}^{-1}$, $P=0.28$ ) were lower in smokers compared to nonsmokers, with only the former being statistically significant. MDA $\left(0.919 \pm 0.32\right.$ vs. $\left.0.647 \pm 0.16 \mu \mathrm{mol} \cdot \mathrm{L}^{-1}, \mathrm{P}=0.05\right)$ and oxLDL were both higher in smokers compared to nonsmokers (229 \pm 94 vs. $\left.110 \pm 62 \mathrm{ng} \cdot \mathrm{mL}^{-1}, \mathrm{p}=0.12\right)$, although only the MDA comparison was of statistical significance. Interestingly, these findings existed despite no differences in dietary intake, including antioxidant micronutrient consumption, between both smokers and nonsmokers.

Conclusion: These data, with specificity to young, novice cigarette smokers, underscore the importance of smoking abstinence. Future studies with larger sample sizes, inclusive of smokers of different ages and smoking histories, are needed to extend these findings.

\section{Introduction}

Production of reactive oxygen species (ROS) in quantities that overwhelm the endogenous antioxidant defense system is referred to as oxidative stress and involves the oxi- dation of molecules in ways that impair cellular function. Chronic oxidative stress has a strong association with numerous disease states including cardiovascular disease (CVD), with several excellent reviews of associated mech- 
anisms relating oxidative stress with CVD recently presented [1-4]. Cigarette smokers have an increased risk of CVD, possibly mediated by elevated levels of oxidized macromolecules owing to heightened ROS production.

Smokers are exposed to significant quantities of ROS in both the gas and tar phase [5]. Further ROS production mediated through inflammatory processes may exacerbate those produced through direct exposure [6]. Previous investigations indicate that smokers have elevated resting biomarkers of oxidative stress compared to nonsmokers [7-9]. Subjects in these studies have traditionally been older, more established smokers, with significant packyear histories $(>20)$.

Potential explanations for the elevated levels of oxidative stress biomarkers in a population of smokers include both increased ROS production from smoke exposure as well as an impaired antioxidant defense system. While cigarette smokers often have lower blood levels of antioxidants compared to nonsmokers, it remains unclear whether or not this occurs primarily as a function of decreased dietary intake of antioxidant rich foods [10-13] or depletion of circulating antioxidants through chronic smoke exposure $[14,15]$. The few studies that controlled for dietary levels of isolated antioxidant nutrients as reviewed by Alberg [14] have suggested that smoking may independently lead to selective depletion in blood levels of the nutrient of focus. Unfortunately, these investigations have not considered "total" antioxidant capacity, rather focusing on vitamin $\mathrm{C}$ or the carotenoids, while many investigations have simply failed to control for dietary factors altogether. Moreover, while blood antioxidant capacity is important, the oxidation of molecules that may contribute to disease, such as low density lipoprotein (LDL), appears most important. Lastly, in the one study that has measured multiple antioxidant vitamins in relation to smoking and dietary intake [15], subjects were older (mean age of 43 years) and more established smokers (mean pack-year history of 27). Therefore, the purpose of this investigation was to determine the independent and combined effect of cigarette smoke exposure and dietary antioxidant intake on blood antioxidant capacity and lipid peroxidation, and to do so in a population of young, novice smokers. It was found that young, novice smokers (pack-year history of 3 \pm 4 ) have lower blood antioxidant capacity and greater lipid peroxidation compared to nonsmokers, despite having similar dietary intake.

\section{Methods \\ Participants}

Fifteen cigarette smokers and 13 nonsmokers volunteered to participate in this investigation. During an initial screening visit, participants completed a health history questionnaire and underwent a physical examination. All participants were sedentary and free of major signs and symptoms suggestive of cardiovascular and pulmonary disease. No participant used nutritional supplements (e.g., antioxidants) or medications (e.g., anti-inflammatory or cardiovascular drugs) that may have affected the dependent variables being measured. Participants needed to regularly smoke $\geq 5$ cigarettes per day to be enrolled as a smoker and needed to be smoking continuously for a minimum of six months prior to being enrolled. Nonsmokers were those participants who had never smoked based on self report, and were not routinely exposed to environmental tobacco smoke in social situations. All experimental procedures were in compliance with the Helsinki Declaration and approved by the University Human Subjects Review Board and participants provided both verbal and written consent prior to participating. Participant characteristics are presented in Table 1.

\section{Blood collection and biochemistry}

Approximately one week following the initial screening visit, participants reported to the laboratory in a fasted state. Smokers were instructed to refrain from smoking for the one hour period prior to reporting to the lab as previously suggested by Dietrich et al. [15]. Venous blood samples were collected via needle and vacutainer following a 10-minute quiet rest period. A portion of whole blood was deproteinated using 5\% metaphosphoric acid and then assayed for total glutathione using commercially available reagents (Northwest Life Science Specialties, Vancouver, WA). The remainder of whole blood was separated immediately to plasma or serum and stored in multiple aliquots at $-80^{\circ} \mathrm{C}$. Plasma antioxidant reducing capacity (ARC; represented as uric acid equivalents) was determined as a measure of blood antioxidant capacity using commercially available reagents (Northwest Life Science Specialties, Vancouver, WA). Serum trolox-equivalent antioxidant capacity (TEAC) was determined using

Table I: Characteristics of smokers and nonsmokers.

\begin{tabular}{lll}
\hline Variable & Smokers $(\mathrm{n}=15)$ & Nonsmokers $(\mathrm{n}=13)$ \\
\hline Age $(\mathrm{yrs})$ & $24 \pm 4$ & $24 \pm 5$ \\
Height $(\mathrm{cm})$ & $173 \pm 8$ & $172 \pm 8$ \\
Weight $(\mathrm{kg})$ & $81 \pm 14$ & $77 \pm 15$ \\
BMI $\left(\mathrm{kg} \cdot \mathrm{m}^{-2}\right)$ & $26.7 \pm 4$ & $25.5 \pm 3$ \\
Resting Heart Rate $(\mathrm{bpm})$ & $70 \pm 3$ & $67 \pm 3$ \\
Resting SBP $(\mathrm{mmHg})$ & $120 \pm 12$ & $116 \pm 10$ \\
Resting DBP $(\mathrm{mmHg})$ & $78 \pm 10$ & $74 \pm 10$ \\
Cigarettes per day & $11 \pm 10$ & NA \\
Years smoking & $6 \pm 5$ & NA \\
Pack-Years & $3 \pm 4$ & NA
\end{tabular}

Note: Values are mean \pm SD. No statistical differences were noted between groups for any of the above variables $(p>0.05)$. BMI, body mass index; SBP, systolic blood pressure; DBP, diastolic blood pressure. 
procedures outlined by the reagent provided (Sigma Chemical, St. Louis, MO). Malondialdehyde (MDA) was analyzed in plasma using the method described by Jentzsch et al. [16]. Plasma oxidized LDL (oxLDL) was determined using an enzyme linked immunosorbent assay (ELISA) procedure (Alpco Diagnostics, Salem, NH). Both MDA and oxLDL were used as markers of lipid peroxidation. Assays were performed in duplicate on first thaw.

\section{Dietary records}

In order to compare dietary intake between smokers and nonsmokers, detailed diet records were maintained by all participants for the seven days prior to providing their blood sample. During the period of recording, participants were instructed to record all food and drink consumed, and were strongly encouraged to consume their normal diets. Using standardized procedures for dietary data collection that our unit has used for several years $[17,18]$, participants were provided with written instructions on how to complete the food records in addition to personal instruction during their screening visit. Upon return of records, each entry was reviewed with participants to assure accuracy. Although the necessity for thorough descriptions by the participant and detailed review by the researchers has been questioned [19], we chose to continue with this protocol until more definitive data appear. These procedures, as well as dietary data entry and management, were overseen by the same research assistant. Records were analyzed for total kilocalories, protein, carbohydrate, fat, vitamin C, vitamin E, vitamin A, B vitamins, and selected minerals using commercially available software (Diet Analysis Plus, ESHA Research, Salem, OR). This analysis allowed for nutrient intake assessment between smokers and nonsmokers.

\section{Statistical analysis}

All data were compared between smokers and nonsmokers using a one-way ANOVA. Effect size calculations for all bloodborne variables were performed using Cohen's D. Regression analysis for the each dependent variable (e.g., glutathione, ARC, TEAC, MDA, and oxLDL) was performed using the following predictor variables: smoking status (smoker/nonsmoker), vitamin C, vitamin A, vita- min E. These antioxidant nutrients were chosen as they have been reported previously to be impacted by cigarette smoke, as well as alter levels of oxidative stress and antioxidant biomarkers. The distribution of data for each predictor was checked for normality prior to inclusion. Pairwise correlations were performed on all predictor variables in order to determine multi-collinearity. If correlations above 0.90 were observed between predictor variables, only the variable with the higher $\mathrm{R}^{2}$ values was included. None of the predictor variables needed to be excluded for this reason. Following these steps, block regression using smoking status and dietary antioxidant intake (vitamin C, vitamin A, vitamin E; as one block) was performed. In a separate analysis, smoking history based on the number of cigarettes smoked per day and the number of years smoked were included as independent predictors of the bloodborne variables. All analyses were performed using JMP statistical software version 4.0 (SAS Institute, Cary, NC). Statistical significance was set at $\mathrm{p}<$ 0.05 . The data are presented as mean \pm SD .

\section{Results}

Antioxidant reducing capacity was lower $(\mathrm{p}=0.019)$ and MDA was higher in smokers compared to nonsmokers ( $\mathrm{p}$ $=0.05)$. Total glutathione $(\mathrm{p}=0.28)$ and TEAC $(\mathrm{p}=0.24)$ were not statistically different between smokers and nonsmokers, although were both slightly lower for smokers. Results for oxLDL approached statistical significance $(\mathrm{p}=$ 0.12 ) and oxLDL was more than two-fold higher in smokers compared to nonsmokers. Effect size calculations for ARC, MDA, and oxLDL were considered to be moderate. Data for all bloodborne variables are presented in Table 2.

Dietary intake for smokers and nonsmokers was not statistically different for total kilocalories, macronutrients or micronutrients ( $\mathrm{p}>0.05$, Table 3). Regression analysis indicated that the classification of smoker (smoker or nonsmoker) contributed to the greatest percentage of the variability in ARC $\left(R^{2}=0.22\right)$, MDA $\left(R^{2}=0.31\right)$, and oxidized LDL $\left(\mathrm{R}^{2}=0.11\right)$ when compared to individual dietary components. This was accounted for primarily by the number of years smoking as opposed to the number of cigarettes smoked per day. For example, within smokers it was noted that the number of years smoking accounted

Table 2: Bloodborne variables for smokers and nonsmokers.

\begin{tabular}{|c|c|c|c|c|}
\hline Variable & Smokers $(n=15)$ & Nonsmokers $(n=13)$ & $P$ value & Effect Size \\
\hline Antioxidant Reducing Capacity $\left(\mathrm{mmol} \cdot \mathrm{L}^{-1}\right)$ & $0.0676 \pm 0.0352$ & $0.1257 \pm 0.0542$ & $0.019 *$ & 0.54 \\
\hline Trolox-Equivalent Antioxidant Capacity $\left(\mathrm{mmol} \cdot \mathrm{L}^{-1}\right)$ & $0.721 \pm 0.120$ & $0.765 \pm 0.130$ & 0.24 & 0.17 \\
\hline Total Glutathione $\left(\mu \mathrm{mol} \cdot \mathrm{L}^{-1}\right)$ & $835 \pm 143$ & $898 \pm 168$ & 0.28 & 0.20 \\
\hline Malondialdehyde $\left(\mu \mathrm{mol} \cdot \mathrm{L}^{-1}\right)$ & $0.919 \pm 0.32$ & $0.647 \pm 0.16$ & $0.05^{*}$ & 0.47 \\
\hline Oxidized Low Density Lipoprotein $\left(\mathrm{ng} \cdot \mathrm{mL}^{-1}\right)$ & $229 \pm 94$ & $110 \pm 62$ & 0.12 & 0.60 \\
\hline
\end{tabular}

Note: Values are mean \pm SD. 
Table 3: Dietary intake during the seven days prior to providing blood sample for smokers and nonsmokers.

\begin{tabular}{|c|c|c|c|c|c|c|c|c|}
\hline Participants & Kcal & Protein & Carbohydrate & Fat & Vitamin C & Vitamin E & Vitamin A & Iron \\
\hline Smokers & $1850 \pm 666$ & $\begin{array}{l}65 \pm 20 \\
(18 \pm 8)\end{array}$ & $\begin{array}{c}242 \pm 85 \\
(51 \pm 8)\end{array}$ & $\begin{array}{l}66 \pm 28 \\
(31 \pm 4)\end{array}$ & $37 \pm 20$ & $4 \pm 2$ & $667 \pm 387$ & $14 \pm 5$ \\
\hline Nonsmokers & $1643 \pm 302$ & $\begin{array}{l}61 \pm 19 \\
(15 \pm 4)\end{array}$ & $\begin{array}{l}214 \pm 55 \\
(52 \pm 10)\end{array}$ & $\begin{array}{l}60 \pm 20 \\
(33 \pm 8)\end{array}$ & $54 \pm 47$ & $5 \pm 3$ & $499 \pm 548$ & $12 \pm 7$ \\
\hline
\end{tabular}

Note: Data are mean \pm SD. Gram quantities for each macronutrient are provided with corresponding percentages in parentheses. Vitamin C, vitamin $\mathrm{E}$, and iron values are provided in $\mathrm{mg}$; vitamin $\mathrm{A}$ values are provided in retinol equivalents. No statistical differences were noted between groups for any measured variable shown above or for any of the $B$ vitamins, vitamin $D$, calcium, sodium, potassium, phosphorous, or zinc ( $P>0.05$ ).

for the greatest variability in ARC $\left(\mathrm{R}^{2}=0.26\right)$ and MDA $\left(\mathrm{R}^{2}=0.22\right)$, although less variability was explained by this regressor in oxLDL $\left(R^{2}=0.12\right)$, glutathione $\left(R^{2}=0.04\right)$, and TEAC $\left(\mathrm{R}^{2}=0.08\right)$. The number of cigarettes smoked per day did not explain a large portion of the variability in any of the dependent variables. Multiple regression with the addition of vitamins $\mathrm{C}, \mathrm{A}$, and $\mathrm{E}$ (as one block) increased the $\mathrm{R}^{2}$ to 0.33 for $\mathrm{ARC}$, to 0.41 for MDA, and to 0.22 for oxLDL. Smoking and dietary intake contributed little to explaining the variability in total blood glutathione and TEAC.

\section{Discussion}

Data from the present study indicate that young, novice smokers (pack-year history of $3 \pm 4$ ) have a lower plasma antioxidant capacity and exhibit a greater degree of lipid peroxidation compared to nonsmokers, despite having similar dietary intake. These data suggest that the act of cigarette smoking may independently promote such negative changes, with the number of years spent smoking contributing most to these findings. While dietary intake, as well as other genetic and environmental factors not determined in this investigation may contribute to these results, it appears that smoking plays a major role in promoting these changes.

It is known that exogenous antioxidant intake from whole food and nutritional supplements may influence both the antioxidant capacity of blood [20] as well as oxidative stress biomarkers [21]. It has been independently reported that smokers consume less antioxidant rich foods compared to nonsmokers [11-13] and have suppressed blood levels of certain antioxidants such as ascorbic acid [15], tocopherol, and superoxide dismutase [22], which may influence the degree of oxidative stress. As such, many investigators have reported elevated levels of oxidative stress biomarkers in smokers compared to nonsmokers [7-9]. However, no previous study has determined the independent and combined contribution of smoking and dietary antioxidant intake on blood antioxidant capacity and oxidative stress biomarkers, in particular within a population of young, novice smokers. Previous studies have included older, more established smokers, as in the work of Dietrich and coworkers [15] in which subjects had a mean age of 43 years and a mean pack history of 27 years. In contrast, our participants had a mean age of 24 years and a mean pack history of only 3 years. While these findings are interesting, they are highly specific to young, novice smokers. Future studies with larger sample sizes, inclusive of smokers of different ages and smoking histories, are needed to extend these findings. In this way, smokers could be classified by age, as well by smoking habit (e.g., light, moderate, and heavy). Using this approach, data would better be able to be generalized to the population at large.

We chose to measure blood antioxidant capacity as well as two common markers of lipid peroxidation, MDA and oxLDL. A great deal of focus has been placed on the oxidative modification of lipids, and in particular LDL and the causal role of oxLDL in the pathophysiology of atherosclerosis $[23,24]$. Oxidized LDL is more atherogenic than native LDL and is taken up by the scavenger receptor system ultimately leading to the generation of foam cells and the development of early lesions [25]. Atherosclerotic lesions in both animal and man have been reported to contain significant oxLDL [26], while antibodies to oxLDL have been found to correlate with the progression of atherosclerosis [27]. Oxidized LDL is also cytotoxic and has the ability to promote endothelial dysfunction, as well as the induction of genes such as interleukin-1 that can induce smooth muscle cell proliferation and promote a procoagulant state [28]. Furthermore, oxLDL may promote platelet adhesion, trigger DNA strand breaks, and promote apoptosis, all of which contribute to the development of atherosclerotic disease [29]. Based on the above, we believe that oxLDL is an important marker to focus on in relation to oxidative stress research. Although we failed to note statistical significance between smokers and nonsmokers with regards to oxLDL, values were more than two-fold higher in smokers and our effect size calculation for this marker was moderate. It is likely that we were underpowered statistically to detect significance in oxLDL. Future studies with larger samples are needed to corroborate our findings. 
It should be noted that despite no differences in dietary variables between smokers and nonsmokers, mean vita$\min \mathrm{C}$, vitamin $\mathrm{E}$, and vitamin A intake was lower than the recommended Dietary Reference Intakes for both groups of participants. The current recommended daily intake of vitamin $\mathrm{C}$ is $75 \mathrm{mg}$ per day for women and $90 \mathrm{mg}$ per day for men 19-50 years of age. Daily vitamin E intake is suggested at $15 \mathrm{mg}$ per day for both men and women, while vitamin A intake is suggested at $700 \mu \mathrm{g}$ per day for women and $900 \mu \mathrm{g}$ per day for men $19-50$ years of age. It is possible that the lower than recommended intake of these vitamins could have promoted a lower antioxidant capacity and higher lipid peroxidation. However, because we found no statistical difference between groups for these variables, we have no reason to believe that one group was affected more than another in this regard. While participants were instructed to record all food and drink consumed during the reporting period, it is possible that underreporting could have occurred. If so, the analyzed values may have been lower than what participants habitually consume. This is indeed a limitation of the present investigation and of using dietary records within a free living environment to determine nutrient intake.

\section{Conclusion}

These findings indicate that young, novice cigarette smokers have lower blood antioxidant capacity and higher lipid peroxidation levels compared to nonsmokers, despite having similar dietary intake. This is the first report to suggest that the act of cigarette smoking, in particular the number of years participating in this activity, may manifest in impaired antioxidant capacity and elevated oxidative stress independent of dietary intake. In particular, these data are in reference to young, novice smokers. It is very possible that more robust findings in relation to nutrient intake would be observed in a population of older, more established smokers. Future study is needed to confirm this hypothesis. Based on previous literature, such changes over time appear to have the potential to promote ill-health and disease within susceptible individuals. Additional studies using larger samples with the inclusion of clinically relevant endpoints are needed to extend these findings.

\section{Competing interests}

The author(s) declare that they have no competing interests.

\section{Authors' contributions}

R. Bloomer was responsible for the study design, oversight of all data collection, biochemical work, statistical analyses, and manuscript preparation.

\section{Acknowledgements}

This work was supported in part by a University of Memphis Faculty Research Grant.

\section{References}

I. Ceriello A, Motz E: Is oxidative stress the pathogenic mechanism underlying insulin resistance, diabetes, and cardiovascular disease? The common soil hypothesis revisited. Arterioscler Thromb Vasc Biol 2004, 24(5):816-823.

2. Chen J, Mehta JL: Role of oxidative stress in coronary heart disease. Indian Heart J 2004, 56(2): I63-I73.

3. Ogita $\mathrm{H}$, Liao J: Endothelial function and oxidative stress. Endothelium 2004, I I(2): I 23-1 32.

4. Stocker R, Keaney JF: Role of oxidative modifications in atherosclerosis. Physiol Rev 2004, 84(4): | 38|- | 478.

5. Pryor WA, Stone K: Oxidants in cigarette smoke. Radicals, hydrogen peroxide, peroxynitrate, and peroxynitrite. Ann $N$ Y Acad Sci 1993, 686: I2-27.

6. Van der Vaart H, Postma DS, Timens W, Ten Haccken NHT: Acute effects of cigarette smoke on inflammation and oxidative stress: a review. Thorax 2004, 59:7I3-72I.

7. Lodovici M, Casalini C, Cariaggi R, Michelucci L, Dolara P: Levels of 8-hydroxydeoxyguanosine as a marker of DNA damage in human leukocytes. Free Radic Biol Med 2000, 28(I): I3-I7.

8. Morrow JD, Frei B, Longmire AW, Gaziano MJ, Lynch SM, Shyr Y, Strauss WE, Oates JA, Roberts LJ: Increase in circulating products of lipid peroxidation ( $F_{2}$-isoprostanes) in smokers. $\mathrm{N}$ Engl J Med 1995, 332: I 198-1203.

9. Yamaguchi Y, Haginaka J, Morimoto S, Fujioka Y, Kunitomo M: Facilitated nitration and oxidation of LDL in cigarette smokers. Eur J Clin Invest 2005, 35(3): I 86-193.

10. Birkett $\mathrm{NJ}$ : Intake of fruits and vegetables in smokers. Public Health Nutr 1999, 2(2):217-222.

II. Ma J, Hampl JS, Betts NM: Antioxidant intakes and smoking status: data from the continuing survey of food intakes by individuals I994-I996. Am J Clin Nutr 2000, 7 I(3):774-780.

12. Marangon K, Herbeth B, Lecomte E, Paul-Dauphin A, Grolier P, Chancerelle Y, Artur Y, Siest G: Diet, antioxidant status, and smoking habits in French men. Am J Clin Nutr 1998, 67(2):231-239.

13. Palaniappan U, Jacobs Starkey L, O'Loughlin J, Gray-Donald K: Fruit and vegetable consumption is lower and saturated fat intake is higher among Canadians reporting smoking. J Nutr 200I, I3 I(7): 1952-1958.

14. Alberg $\mathrm{A}$ : : The influence of cigarette smoking on circulating concentrations of antioxidant micronutrients. Toxicology 2000, 180:121-137.

15. Dietrich M, Block G, Norkus EP, Hudes M, Traber MG, Cross CE, Packer L: Smoking and exposure to environmental tobacco smoke decrease some plasma antioxidants and increase gamma-tocopherol in vivo after adjustment for dietary antioxidant intakes. Am J Clin Nutr 2003, 77(I): I60-166.

16. Jentzsch AM, Bachmann H, Furst P, Biesalski HK: Improved Analysis of Malondialdehyde in Human Body Fluids. Free Radic Biol Med 1996, 20:25I-56.

17. Eck LH, Klesges LM, Klesges RC: Precision and estimated accuracy of two short-term food frequency questionnaires compared with recalls and records. J Clin Epidemiol 1996, 49(10): I I 95-2000.

18. Ward KD, Mays KE, Burstyne MB, Slawson DA, Vukadinovich CM, McClanahan BS, Clemens LH: Reliability and validity of a brief questionnaire to assess calcium intake in female collegiate athletes. Int J Sport Nutr Exerc Metab 2004, I 4:209-22I.

19. Kolar AS, Patterson RE, Neuhouser ML, Frank LL, Standley J, Potter JD, Kristal RR: A practical method for collecting 3-day food records in a large cohort. Epidemiology 2005, 16:579-583.

20. Cao G, Booth SL, Sadowski JA, Prior RL: Increases in human plasma antioxidant capacity after consumption of controlled diets high in fruit and vegetables. Am J Clin Nutr 1998, 68(5): $|08|-1087$.

21. Tesoriere LD, Butera AM, Pintaudi M, Livrea Allegra MA: Supplementation with cactus pear (Opuntia ficus-indica) fruit decreases oxidative stress in healthy humans: a comparative study with vitamin C. Am J Clin Nutr 2004, 80(2):391-395.

22. Zhou JF, Yan XF, Guo FZ, Sun NY, Qian Z], Ding DY: Effects of cigarette smoking and smoking cessation on plasma constituents and enzyme activities related to oxidative stress. Biomed Environ Sci 2000, I3(I):44-55. 
23. Chisolm GM, Steinberg D: The oxidative modification hypothesis of atherogenesis: an overview. Free Radic Biol Med 2000, 28(12): $1815-1826$.

24. Heinecke JW: Oxidants and antioxidants in the pathogenesis of atherosclerosis: implications for the oxidized low density lipoprotein hypothesis. Atherosclerosis 1998, 141:1-I5.

25. Steinberg D: Low density lipoprotein oxidation and its pathobiological significance. J Biol Chem 1997, 272(34):20963-20966.

26. Yla-Herttuala S, Palinski W, Rosenfeld ME, Parthasarathy S, Carew TE, Butler S, Witztum JL, Steinberg D: Evidence for the presence of oxidatively modified low density lipoprotein in atherosclerotic lesions of rabbit and man. I Clin Invest 1989, 84(4): 1086-1095.

27. Salonen JT, Yla-Herttuala S, Yamamoto R, Butler S, Korpela H, Salonen R, Nyyssonen K, Palinski W, Witztum JL: Autoantibody against oxidised LDL and progression of carotid atherosclerosis. Lancet 1992, 339(8798):883-887.

28. Jialal I: Evolving lipoprotein risk factor: lipoprotein(a) and oxidized low-density lipoprotein. Clin Chem 1998, 44(8(B)): $1827-1832$.

29. Sachidanandam K, Fagan SC, Ergul A: Oxidative stress and cardiovascular disease: antioxidants and unresolved issues. Cardiovasc Drug Rev 2005, 23(2): I I5-I 32.

Publish with Bio Med Central and every scientist can read your work free of charge

"BioMed Central will be the most significant development for disseminating the results of biomedical research in our lifetime. "

Sir Paul Nurse, Cancer Research UK

Your research papers will be:

- available free of charge to the entire biomedical community

- peer reviewed and published immediately upon acceptance

- cited in PubMed and archived on PubMed Central

- yours - you keep the copyright

Submit your manuscript here:

http://www.biomedcentral.com/info/publishing_adv.asp
BiolMedcentral 